This item was submitted to Loughborough's Research Repository by the author.

Items in Figshare are protected by copyright, with all rights reserved, unless otherwise indicated.

\title{
Effects of dietary nitrate supplementation on the response to extremity cooling and endothelial function in individuals with cold sensitivity. A double blind, placebo controlled, crossover, randomised control trial
}

\section{PLEASE CITE THE PUBLISHED VERSION}

https://doi.org/10.1016/j.niox.2017.09.005

\section{PUBLISHER}

(C) Elsevier

\section{VERSION}

AM (Accepted Manuscript)

\section{PUBLISHER STATEMENT}

This work is made available according to the conditions of the Creative Commons Attribution-NonCommercialNoDerivatives 4.0 International (CC BY-NC-ND 4.0) licence. Full details of this licence are available at: https://creativecommons.org/licenses/by-nc-nd/4.0/

\section{LICENCE}

CC BY-NC-ND 4.0

\section{REPOSITORY RECORD}

Eglin, Clare, Joseph T. Costello, Stephen Bailey, Mark Gilchrist, Heather Massey, and Anthony I. Shepherd. 2019. "Effects of Dietary Nitrate Supplementation on the Response to Extremity Cooling and Endothelial Function in Individuals with Cold Sensitivity. A Double Blind, Placebo Controlled, Crossover, Randomised Control Trial". figshare. https://hdl.handle.net/2134/26627. 

Effects of dietary nitrate supplementation on the response to extremity cooling and endothelial function in individuals with cold sensitivity. A double blind, placebo controlled, crossover, randomised control trial.

\section{Clare M Eglin ${ }^{1}$, Joseph T Costello ${ }^{1}$, Stephen J Bailey ${ }^{2}$, Mark Gilchrist ${ }^{3}$, Heather Massey ${ }^{1}$,}

${ }^{2}$ School of Sport, Exercise and Health Sciences, Loughborough University, Loughborough, UK, and Exeter Hospital, Exeter, Devon, UK.

Corresponding author:

Dr Anthony Shepherd

Department of Sport and Exercise Science

Spinnaker Building

17 Cambridge Road

18 Portsmouth, UK

PO1 2ER

Email address -ant.shepherd@port.ac.uk

Key words:

Nitrate

23 Nitric oxide

Microvascular

Beetroot 
Abbreviations

ACh acetylcholine

CVC cutaneous vascular conductance

MAP mean arterial pressure

$\mathrm{NFCl}$ non-freezing cold injury

NO• nitric oxide

RSNO S-Nitrosothiols

eNOS endothelial nitric oxide synthase

Word count

Abstract: 261

40

Manuscript:

41

42

\section{Abstract}

Individuals with cold sensitivity have low peripheral skin blood flow and skin temperature possibly due to reduced nitric oxide $(\mathrm{NO} \bullet$ ) bioavailability. Beetroot has a high concentration of inorganic nitrate and may increase NO-mediated vasodilation. Using a placebo-controlled, double blind, randomised, crossover design, this study tested the hypotheses that acute beetroot supplementation would increase the rate of cutaneous rewarming following a local cold challenge and augment endothelium-dependent vasodilation in cold sensitive individuals.

50 Thirteen cold sensitive participants completed foot and hand cooling (separately, in $15{ }^{\circ} \mathrm{C}$ water for 2 minutes) with spontaneous rewarming in $30^{\circ} \mathrm{C}$ air whilst skin temperature and cutaneous vascular conductance (CVC) were measured (Baseline). On two further separate visits, participants consumed $140 \mathrm{ml}$ of either concentrated beetroot juice (nitrate supplementation) or nitrate-depleted beetroot juice (Placebo) 90 minutes before resting seated blood pressure was measured. Endothelial function was assessed by measuring CVC 
at the forearm, finger and foot during iontophoresis of $1 \% \mathrm{w} / \mathrm{v}$ acetylcholine followed by foot and hand cooling as for Baseline.

Plasma nitrite concentrations significantly increased in nitrate supplementation compared to Placebo and Baseline (502 $\pm 246 \mathrm{nmol}^{-\mathrm{L}^{-1}} ; 73 \pm 45 \mathrm{nmol} \mathrm{L}^{-1} ; 74 \pm 49 \mathrm{nmol} . \mathrm{L}^{-1}$ respectively; $n=11 ; P<0.001)$. Resting blood pressure and the response to foot and hand cooling did not differ between conditions (all $P>0.05$ ). Nitrate supplementation did not alter endothelial function in the forearm, finger or foot (all $P>0.05$ ) compared to Placebo.

Despite a physiologically meaningful rise in plasma nitrite concentrations, acute nitrate supplementation does not alter extremity rewarming, endothelial function or blood pressure in individuals with cold sensitivity.

\subsection{Introduction}

Non-freezing cold injury (NFCl) is caused by prolonged exposure to cold, and often cold and wet, conditions. NFCl most commonly affects the feet, although the hands can also be affected (Eglin et al. 2013). Chronic NFCl, which may last for many years, is characterised (in variable combination and severity) by cold sensitivity, numbness, hyperhidrosis and persistent pain which can significantly affect an individual's quality of life (Golden et al. 2013). $\mathrm{NFCl}$ has been reported in individuals following exposure to cold environments such as: mountaineering and hill walking (Imray et al., 2009), diving (Laden et al., 2007), cycling (Fraser and Loftus, 1979), in homeless individuals (Wrenn, 1991) and the elderly (Williams et al., 2005) as well as in individuals working in cold environments, (Mills and Mills, 1993, Cattermole, 1999, Golden et al., 2013).

Although severe $\mathrm{NFCl}$ can be debilitating, its pathophysiology is not fully understood and therefore a definitive diagnostic tool is not available (Eglin et al., 2013). Sub-clinical forms of $\mathrm{NFCl}$ have also been characterised in individuals frequently exposed to cold conditions for short durations during recreational activities such as windsurfing, surfing and open water swimming. These individuals are cold sensitive (their hands and feet are cooler than "normal" individuals and they take longer to rewarm following cold exposure) but are not considered to have a cold injury (Eglin, 2011). As with $\mathrm{NFCl}$ and primary Raynaud's (Gardner-medwin et al., 2001, O'Reilly et al., 1992), this cold sensitivity is associated with a 
reduced basal skin blood flow and a smaller increase in skin blood flow upon rewarming (Davey et al., 2013, Hope et al., 2014). The resultant cooler peripheral skin temperature will result in reduced skin oxygen tension (Sheffield et al., 1996, Montgomery and Horwitz, 1950) and may put these individuals at greater risk of cold injury on subsequent cold exposure (Cattermole, 1999).

Animal models of $\mathrm{NFCl}$ have shown reduced levels of oxygen in the cooled tissues (Montgomery et al., 1954) and that NFCl may be associated with a pro oxidant state (Geng et al., 2015). Local cooling has been shown to inhibit endothelial nitric oxide synthase (eNOS) as well as increase noradrenaline release (Hodges et al., 2006). In addition, eNOS activity has been shown to be positively associated with temperature (Kellogg et al., 2008). Nitric oxide (NO•) is a known vasodilator and plays a fundamental role in the control of skin blood flow (Hodges et al., 2006, Minson et al., 2001). Moreover, NO • released from Snitrosohemoglobin (Stamler et al., 1997) in hypoxic environments plays a key role in regulating the physiological oxygen gradient. We have previously shown that glyceryl trinitrate, a NO donor, increases the rate of rewarming following foot cooling in individuals with cold sensitivity (Hope et al., 2014). However, individuals develop a tolerance to GTN and show diminishing vasodilatory effects with chronic treatment (Needleman and Johnson, 1973). In addition, the deleterious side effects such as headaches (Hsi et al., 2005) suggests that organic nitrates are not optimal long-term therapies for individuals with cold sensitivity.

Leafy green vegetables and particularly beetroot have a high concentration of inorganic nitrate (Bryan and Hord, 2010). These vegetables are thought to be beneficial to cardiovascular health due to their vasodilatory effects (Gilchrist et al., 2010) with recent reports suggesting that tolerance to inorganic nitrate does not occur (as inferred by blood pressure responses) for at least 28 days (Thompson et al., 2017). Inorganic nitrate can act as a source of systemic NO • generation (Lundberg and Govoni, 2004). Briefly, inorganic nitrate is converted to nitrite by facultative anaerobic bacteria on the dorsum of the tongue (Duncan et al., 1995) with small quantities of this nitrite being converted to NO and other nitrogen oxides such as S-Nitrosothiols (RSNO) by the acidic environment of the stomach (Benjamin et al., 1994). The remaining nitrite and RSNO are then absorbed into the circulation where they act as a storage pool for subsequent NO• production (Lundberg and Weitzberg, 2005), which is expedited in hypoxaemia (Cosby et al., 2003), such as that 
observed in cold sensitivity (Davey et al., 2013, Montgomery and Horwitz, 1950, Sheffield et al., 1996, Hope et al., 2014). This enterosalivary pathway and its purported therapeutic effects have been reviewed elsewhere (Lundberg et al., 2008). Inorganic nitrate, in the form of beetroot juice, improves skin blood flow (Levitt et al., 2015), microvascular function (Keen et al., 2014) and lowers blood pressure (BP) in healthy individuals (Webb et al., 2008) and in individuals with hypertension (Kapil et al., 2015) and peripheral arterial disease (Kenjale et al., 2011). In contrast, some studies have shown no effect of nitrate supplementation on vascular health markers despite increases in circulating NO• intermediates in healthy (Bahra et al., 2012, Shepherd et al., 2016) and clinical populations (Gilchrist et al., 2013). However, the potential for beetroot juice to offer an inexpensive, safe and potentially effective intervention to improve peripheral circulation in individuals with cold sensitivity has not been studied. Recently, nitrate supplementation has also been shown to lower sympathetic nerve activity (Notay et al., 2017) and nitrate/nitrite has been shown to restore vascular function when NOS is inhibited (Ferguson et al., 2016, Carlström et al., 2010). Therefore, as cold sensitive individuals exhibit impaired vascular function possibly due to lower eNOS activity and increased sympathetic drive, nitrate supplementation, and the associated increase in the circulating $\mathrm{NO} \bullet$ pool, might help alleviate the associated detrimental effects as shown with organic nitrates (Hope et al., 2014, Anderson et al., 2002).

We hypothesised that compared to baseline and placebo, nitrate supplementation would increase plasma nitrite concentration, the rate of cutaneous rewarming following a local cold challenge and augment endothelium-dependant vasodilation in individuals with cold sensitivity.

\subsection{Methods}

All procedures for this randomised placebo-controlled, double-blind, cross-over designed trial were approved by the University of Portsmouth Science Faculty Research Ethics committee (2016-107A) and all volunteers provided written informed consent prior to participation. All testing took place at the Department of Sport and Exercise Science, University of Portsmouth between January and March 2017 when the outdoor air temperature averaged $5.8 \pm 2.9^{\circ} \mathrm{C}$ at the time of testing (range $0^{\circ} \mathrm{C}$ to $10^{\circ} \mathrm{C}$ ). 


\subsection{Participants}

Participants were recruited based on their self-reported frequent exposure to cold environments (e.g. winter sea swimming, sailing etc.) or often having cold hands and feet. A baseline cold sensitivity test (described below) was conducted to determine whether the participants had cold sensitive feet or hands. This was defined as a toe or finger skin temperature less than $32^{\circ} \mathrm{C}$ prior to the cold water immersion and after 5 minutes of rewarming in $30^{\circ} \mathrm{C}$ air (House et al., 2015, Eglin et al., 2013). Exclusion criteria included; diagnosis of a prior freezing injury, peripheral vascular disease, thalassaemias affecting haemoglobin and / or hepatitis B.

All participants were non-smokers (for at least 1 year). Participants refrained from consuming food high in nitrate the day before testing and were asked to keep a food diary for the 24 hours before their first visit to the laboratory and to replicate this prior to each visit. Participants abstained from alcohol for 24 hours and caffeine for 3 hours prior to testing. The participants also refrained from using any antibacterial mouth wash for 7 days prior to each test as this has been shown to reduce the concentration of oral bacterial that are responsible for the reduction of nitrate to nitrite (Govoni et al., 2008). Female volunteers were asked about their menstrual cycle to determine whether they were in the follicular or luteal phase or whether they were peri- or post-menopausal. However, the phase of the menstrual cycle was not controlled for since reproductive hormone status does not affect the responses to local cooling (Lunt and Tipton, 2014), thermal perception (Lunt and Tipton, 2014) or iontophoresis of acetylcholine (Ketel et al., 2009).

\subsection{Protocol}

The participants attended the laboratory on three separate occasions at the same time of day to reduce any circadian effects. On arrival at the laboratory, resting seated blood pressure was measured using an automated blood pressure monitor (Omron HEM-705C, Omron, Milton Keynes, UK) with the average of the final three measurements from the brachial artery being recorded and used to calculate mean arterial pressure (MAP). On the first visit (Baseline) the participants then undertook a cold sensitivity test (see below) and if they were classified as cold sensitive, a venous blood sample was taken for measurement of 
plasma nitrate and nitrite using the ozone chemiluminescence technique (Sievers NOA 280; Analytix Ltd, Durham, UK) using a protocol adapted from Bateman et al. (2002).

One and a half hours before arriving at the laboratory for the second and third visit, which were separated by a wash-out period of at least 7 days, the participants consumed either $140 \mathrm{ml}$ of concentrated beetroot juice (nitrate supplementation; $11.9 \mathrm{mmol}$ nitrate; Beet it, James White Drinks Ltd., Ashbocking, UK) or nitrate-depleted concentrated beetroot juice as a placebo (Placebo; $0.02 \mathrm{mmol}$ nitrate; Beet it, James White Drinks Ltd., Ashbocking, UK). This dose has been used in previous studies (Shepherd et al., 2016) and results in peak nitrite concentrations between two and three hours (Wylie et al., 2013) coinciding with the testing. The placebo was similar to the nitrate-rich beetroot juice in taste, colour, texture, appearance, odour and packaging (Gilchrist et al., 2014). On arrival at the laboratory the participants' blood pressure was measured, as described above, and a venous blood sample was taken for measurement of plasma nitrate and nitrite. Following this, participants undertook an endothelium function test followed by a cold sensitivity test of their foot and hand (both described below).

\subsection{Cold sensitivity test}

The cold sensitivity test used in this study has been described in detail elsewhere (Eglin et al., 2013, Hope et al., 2014). Participants entered a climatic chamber controlled at an air temperature of $30.3(0.4){ }^{\circ} \mathrm{C}$, removed their shoes and socks, and rested in a semirecumbent position for 15 minutes. They then exercised on a cycle ergometer (874E, Monark, Sweden) for 12 minutes at an external work rate of $50 \mathrm{~W}$ (previously shown to improve the reliability of the test, (Eglin et al., 2013). Following the 12 minutes cycling, the participant then rested in a semi-recumbent position for 5 minutes whilst resting toe skin temperature and blood flow were recorded.

The participant's left foot was then placed in a plastic bag and immersed in a water bath stirred and maintained at $15.1 \pm 0.2{ }^{\circ} \mathrm{C}$ to the point of their mid-malleoli for 2 minutes. After the immersion period, the plastic bag was removed and rewarming monitored for 10 minutes whilst the participant remained resting in a semi-recumbent position. 
The participant then rested in a seated position for 5 minutes whilst finger skin temperature and blood flow was recorded. The participant, still seated, placed their left hand in a plastic bag and immersed it to the level of the wrist in water at $15.0 \pm 0.2^{\circ} \mathrm{C}$ for 2 minutes. After the immersion period, the plastic bag was removed and rewarming monitored for 10 minutes whilst the participant remained resting in a seated position with their arm supported by an arm rest.

\subsubsection{Measurements}

Skin blood flow was measured using a laser Doppler probe (VP1T / 7, Moor Instruments, UK) placed on the Great toe pads during foot immersion and on the pads of the thumbs during hand immersion. Skin blood flow was analysed using minute averages before, during and after immersion (rewarm period) and expressed as cutaneous vascular conductance (CVC = skin flux/MAP; flux $\mathrm{mmHg}^{-1}$ ). CVC was analysed between conditions at the following time points: pre immersion, 5 and 10 min of rewarming.

Skin temperature was measured using an infrared camera (A320G, FLIR systems, UK) according to the guidelines described in (Moreira et al., 2017). The camera was positioned $1.0 \mathrm{~m}$ away from the sole of the foot and $0.7 \mathrm{~m}$ away from the palm of the hand and recorded using the spot analysis function on the FLIR software (FLIR systems, UK) prior to immersion and every minute during the 10 minute rewarming periods. Great toe, coldest toe, mean toe, thumb and mean finger skin temperature were analysed between conditions at the following time points: pre immersion, 5 and $10 \mathrm{~min}$ of rewarming. The coefficient of variation in our laboratory for the cold sensitivity test is $2.7 \%$ for the finger skin temperatures and $8.7 \%$ for the toe skin temperatures (unpublished data, $n=13$ ).

Blood pressure was measured on the right arm prior to foot and hand immersion and at the end of both rewarming periods using an automated blood pressure monitor (Omron HEM705C, Omron, Milton Keynes, UK) for calculation of MAP.

Thermal sensation and comfort were measured using $20 \mathrm{~cm}$ scales $(0=$ very cold/uncomfortable; 10 = neutral; 20 = very hot/comfortable; modified from Zhang et al. (2004)) and recorded prior to immersion, during immersion and every 2 minutes of the rewarming period. Pain sensation was recorded using a subjective numerical rating scale 
(NRS) for pain (0 no pain, 10 unimaginable, unspeakable pain; (Ferreira-Valente et al., 2011)) at the same time points.

\subsection{Endothelium function test}

236

Following an acclimation period of at least 20 minutes, acetylcholine (ACh) was delivered transdermally using iontophoresis to three sites in the following order: volar aspect of the left forearm, middle phalanx of the middle finger of the left hand and dorsal aspect of the left foot as previously described (Maley et al. 2017). Briefly, a perspex ring containing the anode was attached to the skin site with the cathode attached using a gel pad at the wrist or ankle. Both electrodes were connected to a battery powered iontophoresis controller (MIC 2, Moor Instruments, UK). The anode chamber (8 $\mathrm{mm}$ inner diameter) was filled with approximately $0.5 \mathrm{~mL}$ of $\mathrm{ACh}$. ACh was dissolved into sterile water for injection (Braun, Melsungen, Germany) to yield a concentration of $1 \%$. The protocol consisted of eight pulses: four pulses of $25 \mu \mathrm{A}$ followed by a single pulse of $50 \mu \mathrm{A}, 100 \mu \mathrm{A}, 150 \mu \mathrm{A}$ and a final pulse of $200 \mu \mathrm{A}$ applied for 20 seconds with 60 second intervals between each pulse where no current was applied. After an interval of 5 minutes the protocol was repeated on the next skin site. The tests were conducted at a room temperature of $23.2(0.4){ }^{\circ} \mathrm{C}$.

\subsubsection{Measurements}

Skin blood flow was measured using a laser Doppler probe (VP1T / 7, Moor Instruments, UK) connected to a laser Doppler perfusion monitor (moor VMS-LDF, Moor Instruments, UK). Flux data from the laser Doppler and iontophoresis controller was recorded using a data acquisition system and software (Powerlab and LabChart 7, AD Instruments, Australia). The laser Doppler probe was placed into the perspex ring used for iontophoresis on the forearm, finger, dorsal foot and on the corresponding site on the contra-lateral limb. Skin blood flow responses were expressed as CVC.

Average skin blood flow in response to iontophoresis of ACh was calculated over the final 20 seconds of the interval between successive pulses and between 40 to 60 seconds after the final pulse (Maley et al., 2017). These responses were expressed as absolute CVC as baseline CVC did not differ between conditions for any site. ED ${ }_{50}$, expressed as $95 \%$ confidence intervals, was calculated using GraphPad (Version 5, USA). Maximum skin blood flow and 
area under the curve (AUC) were calculated for each participant. The point at which the skin blood flow was at a maximum point was not always identified following the final pulse therefore maximum skin blood flow was taken from wherever it was highest. Skin temperature was measured adjacent to the iontophoresis site using a skin thermistor (Grants Instruments, Cambridge) and recorded on a data logger (Grants Instruments, Cambridge). Blood pressure was measured on the contralateral arm to iontophoresis using an automated blood pressure monitor (Omron HEM-705C, Omron, Milton Keynes, UK) before and after each ACh dose response curve for calculation of MAP.

\subsection{Sample size and randomisation}

271

An a priori sample size calculation was performed based on data from our previous study on the effect of GTN in cold sensitive individuals (Hope et al. 2013) which showed a $4.2 \pm 3.0^{\circ} \mathrm{C}$ change in skin temperature 10 minutes post immersion during the cold sensitivity test. For $90 \%$ power and an $\alpha$-level of $5 \%$ (two tailed) it was calculated that 13 participants were required.

A computer programme generated a random sequence that was used to assign each participant to begin the trial in one of two arms. Participants were then supplied with the requisite juice (in a sealed, opaque envelope prepared by individuals not involved in the trial) which was counter-balanced and blinded from the participants and researchers.

\subsection{Data analysis}

As with other studies using this technique (Maley et al., 2017) some individuals had high skin resistance which meant that it was not possible to deliver all of the current pulses in each skin site for all participants. Therefore, only those who were able to receive the first pulse of iontophoresis were included in analyses. Where an incomplete current response curve was delivered (due to high skin resistance at the higher currents), the number of pulses used in the analysis was the same within individual for both conditions. A blood sample was not obtained from two participants due to technical difficulties and therefore $n=11$ for Baseline and $n=12$ for Placebo and nitrate supplementation for plasma nitrate and nitrite concentrations. 
Assumption of normal distribution of data was assessed using descriptive methods (skewness, outliers, and distribution plots) and inferential statistics (Shapiro-Wilk test). Where normality was not met, nonparametric tests were performed. For the cold sensitivity test, statistical differences were assessed using repeated measures ANOVAs (condition [Baseline, Placebo, nitrate supplementation] * time [pre immersion, $5 \mathrm{~min}, 10 \mathrm{~min}$ ]) for toe skin temperatures, thumb and Great toe skin blood flows. Finger skin temperatures, thermal comfort, thermal sensation and pain were analysed using Friedman tests. For the endothelial function test, maximum CVC, AUC and skin temperature were analysed using ANOVAs (condition [Baseline, Placebo, nitrate supplementation] * skin site [forearm, finger, foot]). $E D_{50}$ values were analysed using paired samples t-test. Plasma nitrate and nitrite concentrations were analysed using a one way ANOVA. Where appropriate, post-hoc tests were conducted using pairwise comparisons with Bonferroni corrections. Data are presented as mean (SD), unless otherwise stated. Statistical analysis was performed on SPSS version 22 (Chicago, IL) and statistical difference was accepted as $P<0.05$.

\subsection{Results}

Twenty volunteers (10 women, 10 men) gave written informed consent to participate in this trial. Following the baseline cold sensitivity test, 6 individuals (5 women, 1 man; age $25.8 \pm$ $4.2 \mathrm{y}$; height $1.71 \pm 0.13 \mathrm{~m}$; body mass $77.7 \pm 17.7 \mathrm{~kg}$ ) were withdrawn from the trial as they did not meet the skin temperature requirements to be classified as cold sensitive (House et al., 2015) (Figure 1). Fourteen individuals (Figure 1a) were randomised to start in either the nitrate supplementation arm or the placebo arm. One individual was subsequently withdrawn following randomisation (nitrate supplementation first, placebo second) due to use of mouthwash during the intervention period. Therefore, thirteen cold sensitive individuals completed the study (4 women, 9 men; age $34.5 \pm 13.2$ y; height $1.77 \pm 0.07 \mathrm{~m}$; body mass $85.0 \pm 15.9 \mathrm{~kg}$ ). Consistent with our previous findings (Shepherd et al., 2016) the beetroot juice was well tolerated and no adverse events (other than beeturia and discoloured stools) were reported, neither could the participants identify whether they had ingested the placebo or beetroot juice. 
Enrollment

Allocation

Follow-Up

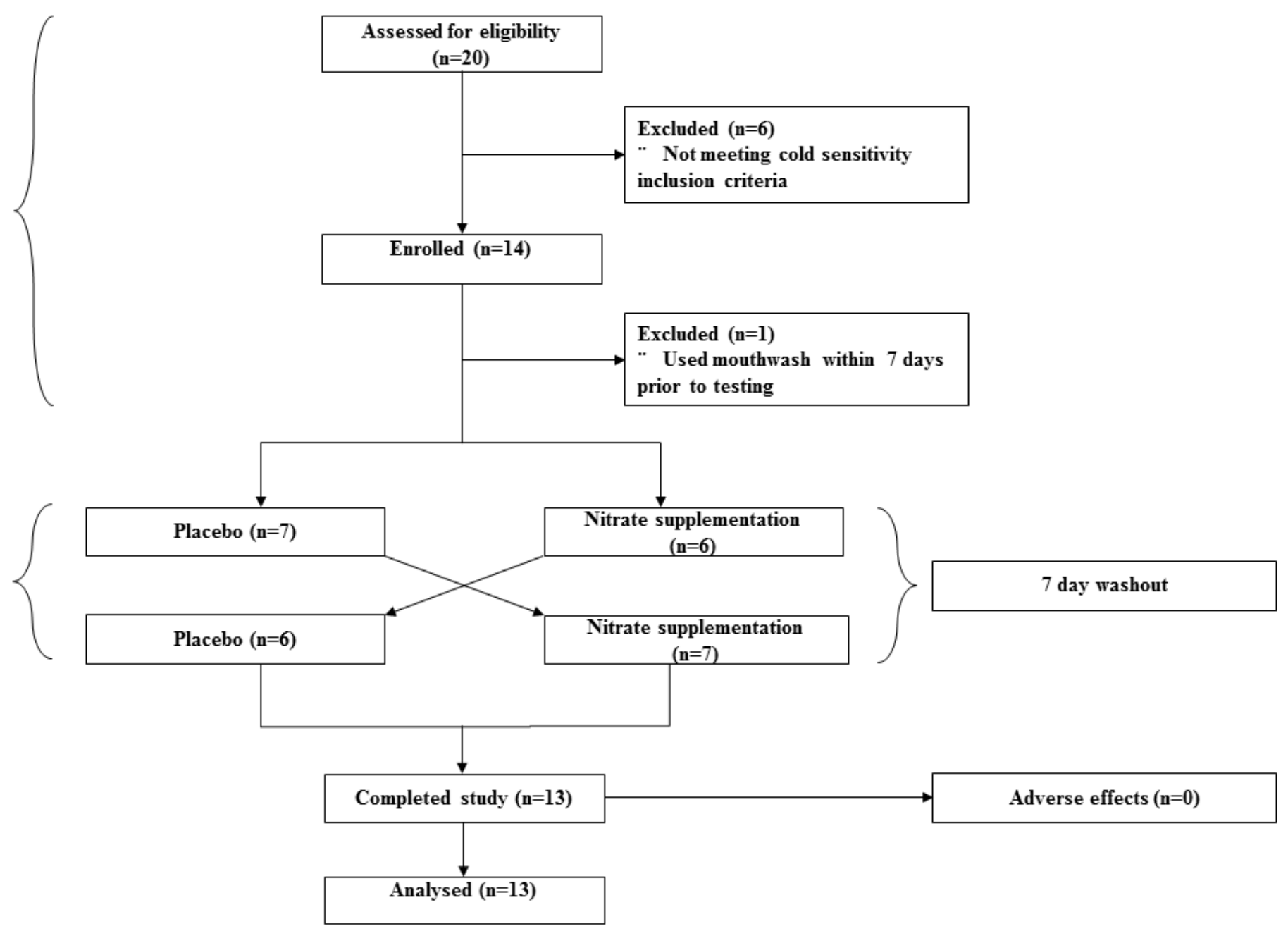




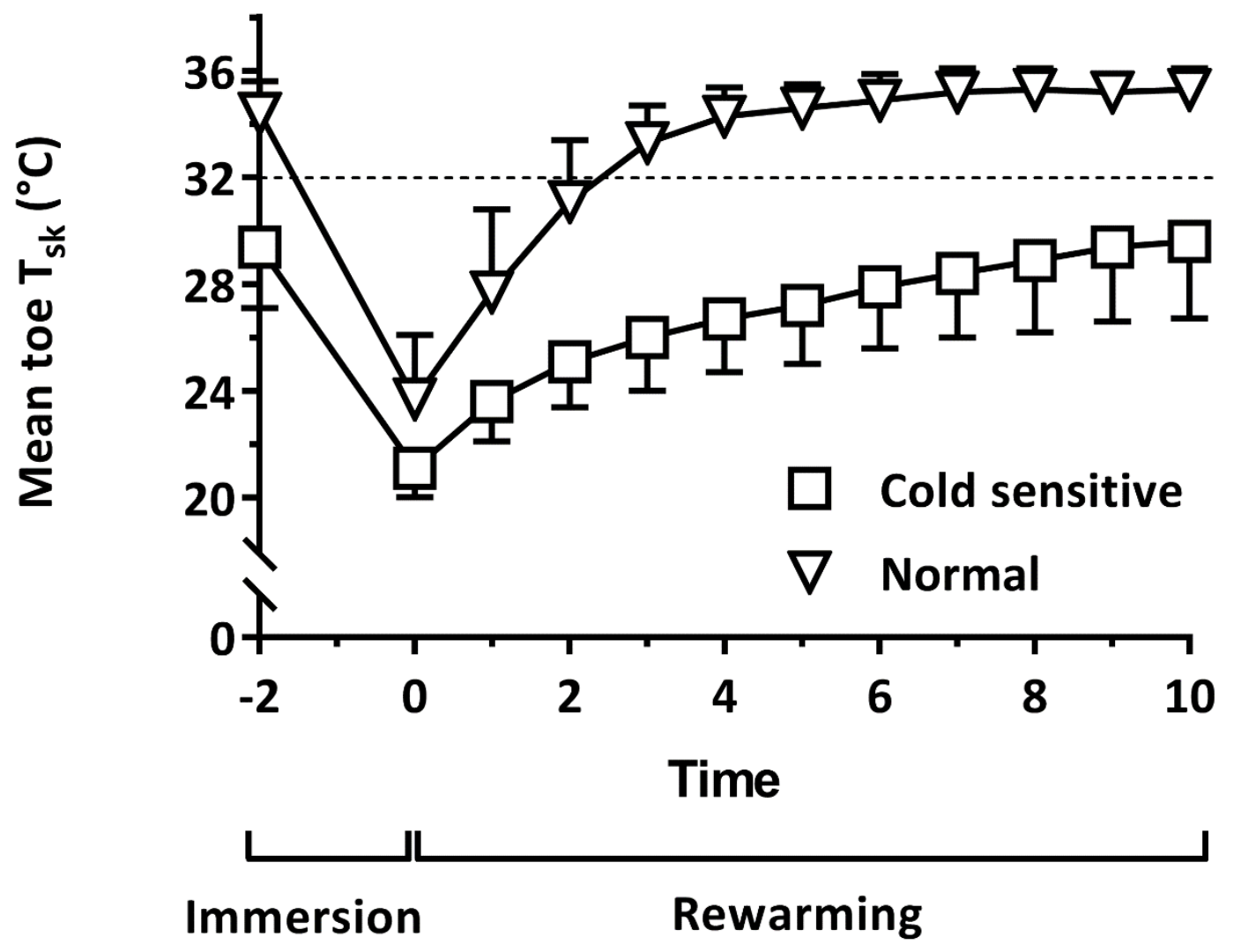

Figure 1B

Figure 1. Participant flow through the trial $(A)$ and average $(S D)$ mean toe skin temperature during the Baseline cold sensitivity test in individuals with $(n=13)$ and without cold sensitivity $(n=6)$ (B). The dotted line represents the cut off skin temperature $\left(T_{s k}\right)$ preimmersion (-2 minutes) and at 5 minutes of rewarming used for determining cold sensitivity.

\subsection{Plasma nitrate and nitrite concentrations}

There was a statistically significant rise in plasma nitrate (Baseline, $53.1 \pm 29.4 \mu \mathrm{M}$; Placebo, $50.5 \pm 24.3 \mu \mathrm{M}$; nitrate supplementation, $\left.756.8 \pm 175.2 \mu \mathrm{M} ; \mathrm{F}_{(2,20)}=198.1, P<0.001\right)$ and nitrite (Baseline, $73.7 \pm 48.8 \mathrm{nM}$; Placebo, $73.5 \pm 44.5 \mathrm{nM}$; nitrate supplementation, $501.5 \pm$ $\left.245.8 \mathrm{nM} ; \mathrm{F}_{(2,20)}=33.6, P<0.001\right)$ following nitrate supplementation when compared to Placebo and Baseline (Figure 2). 

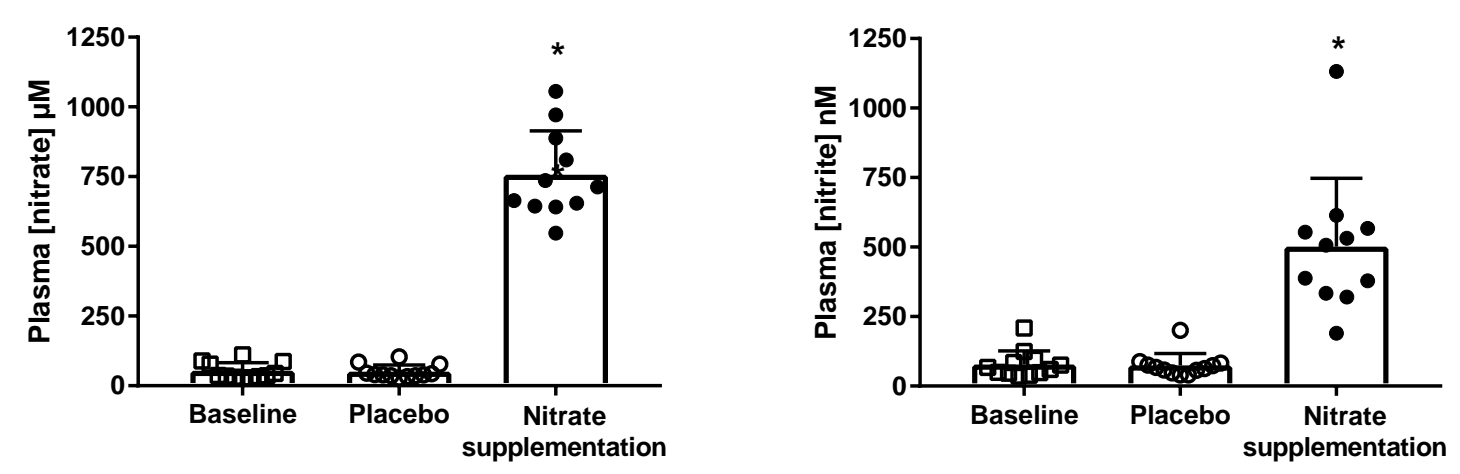

334

335

336

337

338

339

340

341

342

343

344

Figure 2. Mean (SD) and individual plasma nitrate $(A)$ and nitrite $(B)$ concentrations in the Baseline, Placebo and nitrate supplementation conditions $(n=11){ }^{*} P<0.001$ significantly different from Placebo and Baseline.

\subsection{Cold sensitivity test}

There was no effect of nitrate supplementation on skin blood flow in the Great toe $(F(2,24)=$ 1.31, $P=0.289)$, or thumb $\left(\mathrm{F}_{(2,24)}=0.42, P=0.660\right.$; Figure 3$)$ when compared to Placebo or Baseline.

Skin blood flow was significantly different across time for the Great toe $\left(F_{(2,24)}=6.79, P=\right.$ $0.005)$ with a lower CVC observed at 5 min rewarming compared to pre-immersion $(P=$ 0.002; Figure 3A). Thumb skin blood flow also differed across time $\left(F_{(2,24)}=9.39, P=0.001\right)$ with CVC being lower at 5 and 10 min of rewarming compared to pre-immersion $(P=0.025$ and $P=0.016$ respectively; Figure $3 C$ ).

There was no interaction between time and condition for skin blood flow in either the Great toe $\left(F_{(4,48)}=1.58, P=0.195\right)$ or thumb $\left(F_{(4,48)}=0.62, P=0.650\right)$ when nitrate supplementation was compared to Placebo and Baseline (Figure 3 and Table 1).

There was no effect of nitrate supplementation on skin temperature of the Great toe $(F(2,24)$ $=0.70, P=0.51)$, coldest toe $\left(F_{(2,24)}=0.81, P=0.46\right)$, mean toe $\left(F_{(2,24)}=0.61, P=0.55\right)$, or mean finger (pre immersion: $X^{2}{ }_{(2)}=2.57, P=0.27,5$ minutes rewarming: $X^{2}{ }_{(2)}=2.63, P=$ 0.27 , or 10 minutes rewarming: $X^{2}(2)=2.47, P=0.29$ ).

Skin temperature was significantly different across time for the Great toe $\left(F_{(2,24)}=14.8, P<\right.$ $0.001)$, coldest toe $\left(F_{(2,24)}=18.8, P<0.001\right)$ and mean toe $\left(F_{(2,24)}=35.2, P<0.001\right)$. Skin 
temperature after 5 minutes of rewarming was colder than pre immersion $(P=0.028 ; P=$ $0.001 P<0.001$ respectively) but had returned to pre-immersion temperatures after 10 minutes $(P=0.318 ; P=1.00 ; P=1.00$ respectively $)$.

There was no interaction between time and condition for skin temperature (Great toe: $F(4$, 48) $=1.60, P=0.19 ;$ coldest toe $F_{(4,48)}=1.81, P=0.14 ;$ mean toe $\left.F_{(4,48)}=0.81, P=0.52\right)$
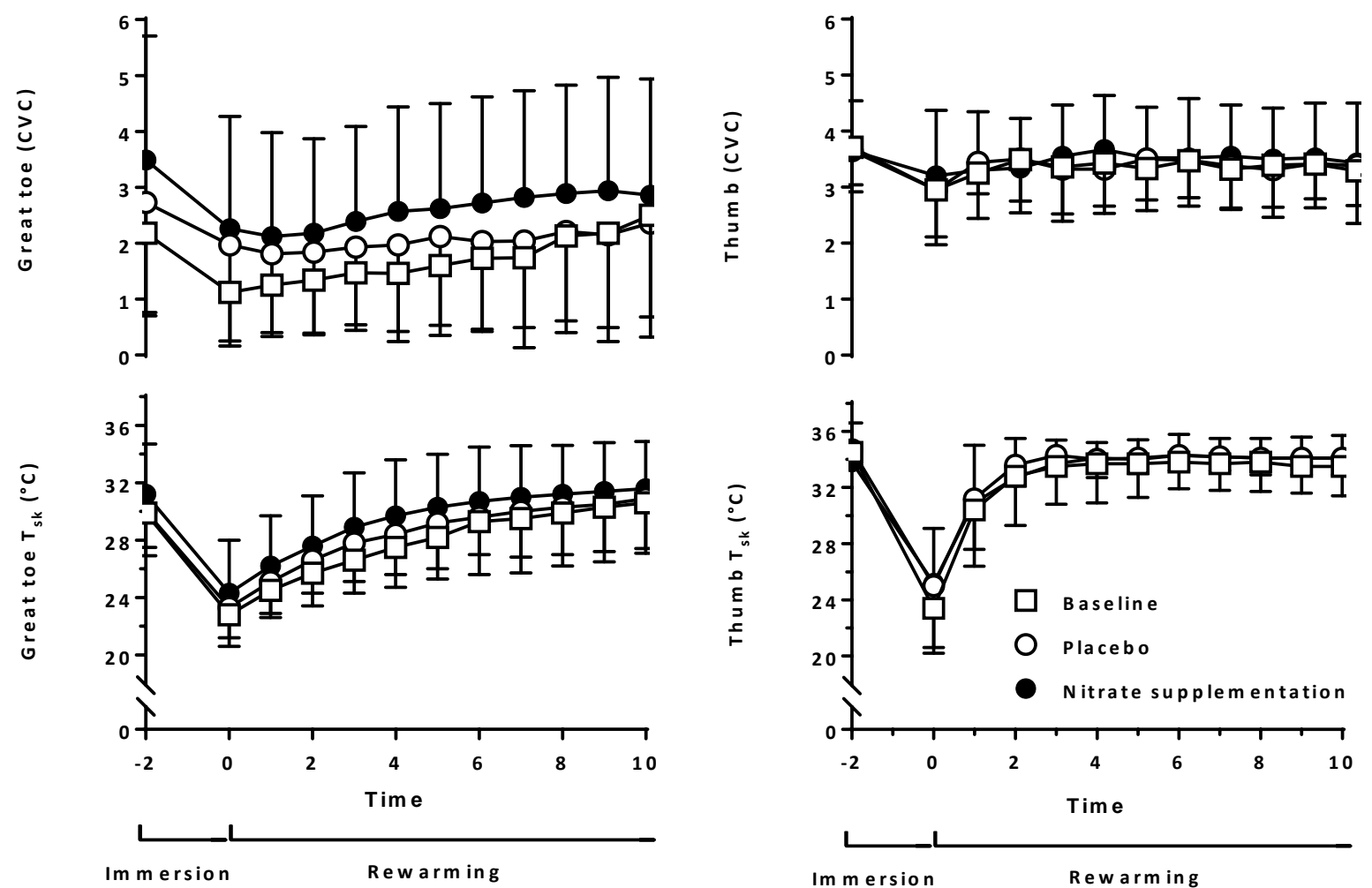

1).

Figure 3. Skin blood flow and temperature during the cold sensitivity test of the foot and hand in the Baseline, Placebo and nitrate supplementation conditions. Mean (SD) cutaneous vascular conductance $(C V C)$ in the Great toe $(A)$ and thumb (B) and skin temperature $\left(T_{s k}\right)$ in the Great toe (C) and thumb (D) are shown $(n=13)$. 
Table 1. Mean (SD) toe, coldest toe and mean finger skin temperature $\left(T_{s k}\right)$ during the cold

\begin{tabular}{|c|c|c|c|c|}
\hline & \multicolumn{3}{|c|}{ Rewarming } \\
\hline & & Pre immersion & 5 minutes & 10 minutes \\
\hline \multirow{3}{*}{$\begin{array}{c}\text { Mean toe } T_{s k} \\
\left({ }^{\circ} \mathrm{C}\right)\end{array}$} & Baseline & $29.4 \pm 2.4$ & $27.2 \pm 2.3$ & $29.6 \pm 3.1$ \\
\hline & Placebo & $30.0 \pm 3.2$ & $28.7 \pm 4.0$ & $30.3 \pm 3.9$ \\
\hline & Nitrate supplementation & $30.8 \pm 3.5$ & $29.0 \pm 3.7$ & $30.7 \pm 3.4$ \\
\hline \multirow{3}{*}{$\begin{array}{c}\text { Coldest toe } T_{\text {sk }} \\
\left({ }^{\circ} \mathrm{C}\right)\end{array}$} & Baseline & $28.2 \pm 2.3$ & $25.8 \pm 1.9$ & $28.5 \pm 3.2$ \\
\hline & Placebo & $28.6 \pm 3.3$ & $27.6 \pm 4.2$ & $29.2 \pm 4.2$ \\
\hline & Nitrate supplementation & $29.6 \pm 3.6$ & $28.1 \pm 3.4$ & $29.6 \pm 3.4$ \\
\hline \multirow{3}{*}{$\begin{array}{c}\text { Mean finger } T_{s k} \\
\left({ }^{\circ} \mathrm{C}\right)\end{array}$} & Baseline & $34.3 \pm 1.7$ & $33.1 \pm 3.3$ & $33.0 \pm 3.0$ \\
\hline & Placebo & $34.6 \pm 1.4$ & $33.2 \pm 3.1$ & $33.6 \pm 2.3$ \\
\hline & Nitrate supplementation & $34.5 \pm 1.2$ & $33.7 \pm 1.8$ & $34.0 \pm 1.9$ \\
\hline
\end{tabular}
point during the cold sensitivity test between conditions (Table 2). 
Table. 2. Thermal sensation, thermal comfort and pain in the foot and hand during the cold sensitivity test in the Baseline, Placebo and nitrate supplementation conditions $(n=13)$. Average rewarm is the mean vote over the last 8 minutes of rewarming.

\begin{tabular}{|c|c|c|c|c|c|c|}
\hline & & Condition & $\begin{array}{c}\text { Pre } \\
\text { immersion }\end{array}$ & $\begin{array}{c}\text { During } \\
\text { immersion }\end{array}$ & $\begin{array}{l}\text { Immediately } \\
\text { after immersion }\end{array}$ & Average rewarm \\
\hline \multirow{9}{*}{ Foot } & \multirow{3}{*}{$\begin{array}{l}\text { Thermal } \\
\text { sensation }\end{array}$} & Baseline & $12.0 \pm 2.2$ & $4.9 \pm 2.0$ & $6.8 \pm 2.7$ & $10.0 \pm 2.1$ \\
\hline & & Placebo & $12.2 \pm 2.5$ & $4.5 \pm 1.5$ & $6.3 \pm 1.9$ & $10.3 \pm 1.9$ \\
\hline & & Nitrate supplementation & $13.3 \pm 2.1$ & $4.8 \pm 1.9$ & $6.5 \pm 1.7$ & $10.0 \pm 1.4$ \\
\hline & \multirow{3}{*}{$\begin{array}{l}\text { Thermal } \\
\text { comfort }\end{array}$} & Baseline & $14.7 \pm 1.9$ & $9.5 \pm 4.6$ & $10.9 \pm 4.4$ & $13.1 \pm 2.9$ \\
\hline & & Placebo & $13.4 \pm 3.3$ & $8.5 \pm 3.0$ & $10.9 \pm 4.1$ & $13.6 \pm 3.1$ \\
\hline & & Nitrate supplementation & $13.4 \pm 3.7$ & $8.5 \pm 3.8$ & $9.9 \pm 3.8$ & $12.8 \pm 3.0$ \\
\hline & \multirow{3}{*}{ Pain } & Baseline & $0.8 \pm 1.0$ & $0.4 \pm 0.7$ & $0.1 \pm 0.3$ & $0 \pm 0$ \\
\hline & & Placebo & $0.5 \pm 0.8$ & $0.2 \pm 0.6$ & $0 \pm 0$ & $0 \pm 0$ \\
\hline & & Nitrate supplementation & $0.9 \pm 1.1$ & $0.5 \pm 0.8$ & $0.1 \pm 0.3$ & $0 \pm 0$ \\
\hline \multirow{9}{*}{ Hand } & \multirow{3}{*}{$\begin{array}{l}\text { Thermal } \\
\text { sensation }\end{array}$} & Baseline & $12.7 \pm 2.4$ & $4.5 \pm 1.6$ & $6.3 \pm 2.9$ & $11.0 \pm 2.7$ \\
\hline & & Placebo & $12.7 \pm 2.0$ & $4.4 \pm 1.5$ & $5.9 \pm 1.9$ & $11.0 \pm 2.1$ \\
\hline & & Nitrate supplementation & $11.8 \pm 2.0$ & $5.2 \pm 1.8$ & $6.5 \pm 2.4$ & $11.5 \pm 2.1$ \\
\hline & \multirow{3}{*}{$\begin{array}{l}\text { Thermal } \\
\text { comfort }\end{array}$} & Baseline & $14.6 \pm 2.3$ & $7.8 \pm 3.8$ & $8.5 \pm 4.6$ & $12.8 \pm 2.3$ \\
\hline & & Placebo & $14.0 \pm 3.2$ & $8.7 \pm 3.7$ & $10.3 \pm 4.0$ & $13.5 \pm 3.0$ \\
\hline & & Nitrate supplementation & $14.3 \pm 3.1$ & $7.9 \pm 3.9$ & $9.7 \pm 4.1$ & $13.2 \pm 2.5$ \\
\hline & \multirow{3}{*}{ Pain } & Baseline & $0.9 \pm 0.9$ & $0.7 \pm 0.9$ & $0.1 \pm 0.3$ & $0 \pm 0$ \\
\hline & & Placebo & $0.9 \pm 1.2$ & $0.3 \pm 0.6$ & $0.0 \pm 0.8$ & $0 \pm 0$ \\
\hline & & Nitrate supplementation & $0.8 \pm 1.1$ & $0.5 \pm 1.0$ & $0.1 \pm 0.3$ & $0 \pm 0$ \\
\hline
\end{tabular}

\subsection{Endothelial function}

392 Skin temperature during ACh iontophoresis was similar in both the Placebo and nitrate supplementation conditions $\left(F_{(1,11)}=0.30, P=0.59 ; F_{(2,22)}=0.54, P=0.58\right.$; Table 3$)$. As 
394

395

396

397

398

399

400

401

402

403

404

405

406

407

408

409

410

411

expected skin temperature was different between skin sites, with the foot being $3.6^{\circ} \mathrm{C}$ colder than the forearm and $2.6^{\circ} \mathrm{C}$ colder than the finger $\left(F_{(2,22)}=14.7, P<0.001\right.$; Table 3$)$.

Average CVC prior to iontophoresis was similar between conditions, for the forearm $(n=12$, $0.13 \pm 0.08$ flux.mmHg${ }^{-1}, P=0.59$ ), the finger ( $n=12,0.66 \pm 0.53$ flux.mmHg-1,$P=0.60$ ) and the foot ( $n=13,0.13 \pm 0.09$ flux.mmHg${ }^{-1}, P=0.99$ ). There was no effect of nitrate supplementation on the vasodilatory dose response to transdermal delivery of ACh in the forearm, finger or foot (Figure 4). Maximum skin blood flow $\left(F_{(1,11)}=0.01, P=0.92\right)$ and $\operatorname{AUC}\left(F_{(1,11)}=0.32, P=0.59\right)$ were similar between Placebo and nitrate supplementation (Table 3) and no significant interactions were observed (maximum blood flow: $F_{(2,22)}=1.84$, $P=0.18$; AUC: $\left.F_{(2,22)}=0.66, P=0.53\right)$. No differences were seen in $\operatorname{ED}_{50}$ for the forearm $(P=$ $0.63)$, finger $(P=0.62)$ or foot $(P=0.30)$ between Placebo and nitrate supplementation (Table 3). However there was a difference between skin sites in the magnitude of the vasodilation to ACh (maximum skin blood flow: $F_{(2,22)}=19.7, P<0.001$; AUC: $F_{(2,22)}=14.3, P$ $<0.001$; Figure 4 and Table 3).

Table 3. Skin blood flow response to iontophoresis of ACh on the forearm, finger and foot in the Placebo and nitrate supplementation conditions. Data are given as mean \pm SD for maximum CVC, area under the curve (AUC) and skin temperature $\left(T_{s k}\right)$ and $95 \%$ confidence intervals are given for the $E D_{50}$.

$$
\text { n Maximum (CVC) }
$$

Placebo

13

$2.0 \pm 1.0$

$2.3 \pm 0.7$

$3.3 \pm 1.6$

12

Placebo

Nitrate supplementation 12

Placebo

Nitrate supplementation

13

13
$3.1 \pm 1.5$

$1.2 \pm 0.8$

$1.0 \pm 0.7$
$E D_{50}(\mu \mathrm{A})$

75.9 to 118.8

69.2 to 111.1

73.4 to 109.3

67.3 to 102.8

105.0 to 147.6

119.3 to 167.7
AUC

$9.6 \pm 7.2$

$30.2 \pm 1.2$

$10.6 \pm 5.3$

$30.1 \pm 1.0$

$16.8 \pm 11.1$

$29.5 \pm 3.3$

$15.1 \pm 9.3$

$28.8 \pm 3.3$

$4.7 \pm 3.1 \quad 26.5 \pm 1.9$

$4.0 \pm 2.8$

$26.6 \pm 2.0$ 
A

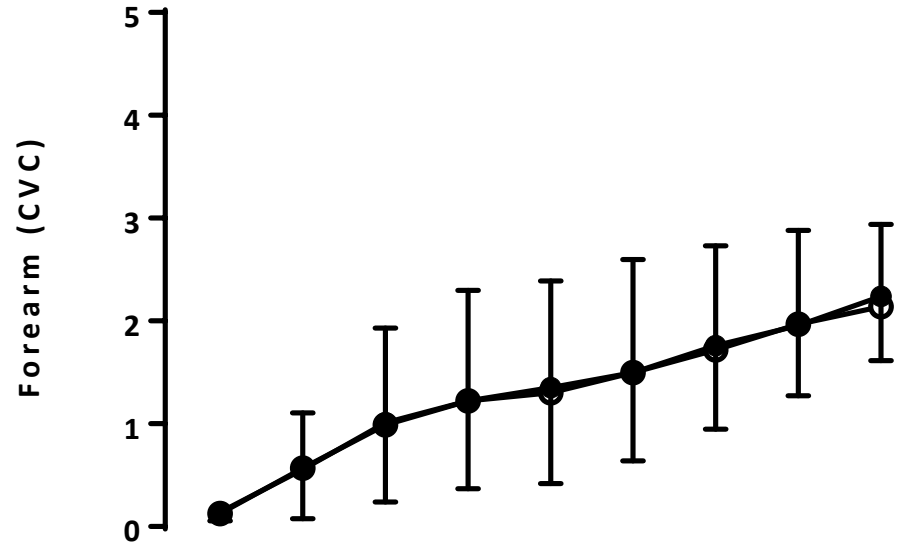

B

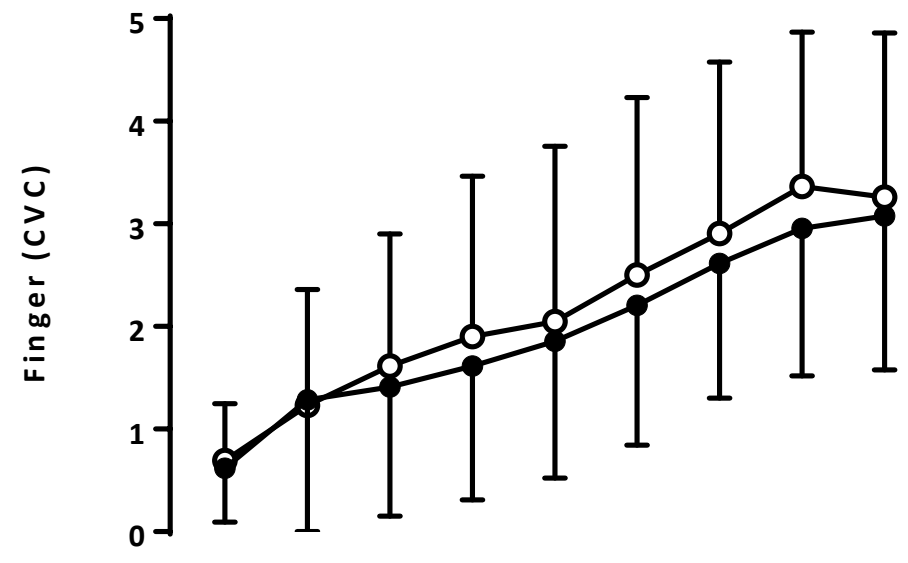

C

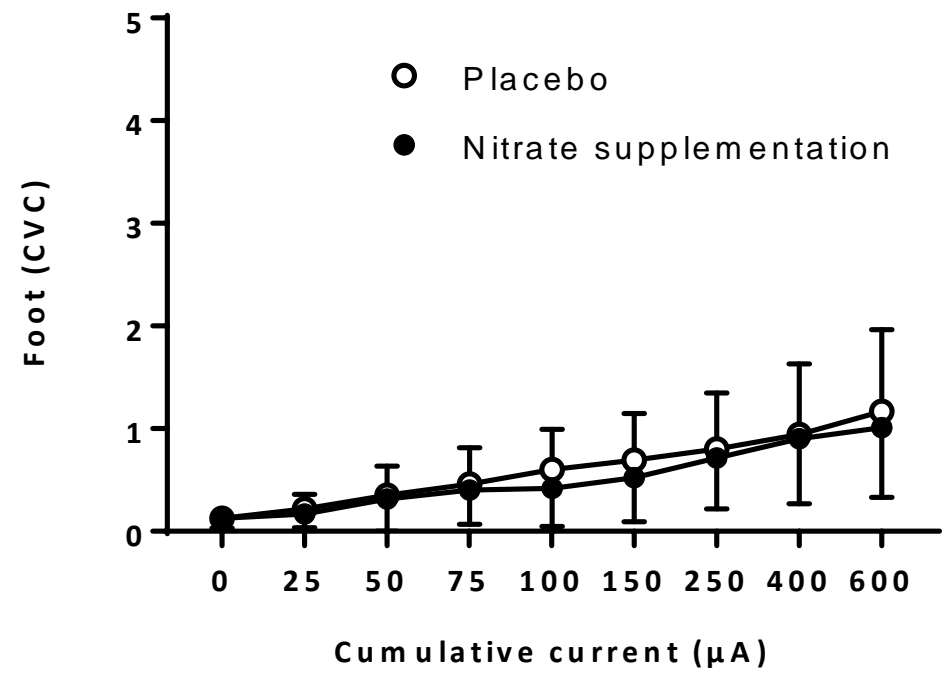

Figure 4. Cutaneous vascular conductance following iontophoresis of ACh on the forearm

$(A)$, finger (B) and foot (C) in the Placebo and nitrate supplementation conditions $(n=13$

416 participants), for finger CVC, $n=12$ at cumulative current 400 and $600 \mu \mathrm{A}$ ). 
There was no effect of nitrate supplementation on systolic blood pressure (Baseline, $123 \pm$ $12 \mathrm{mmHg}$, Placebo $121 \pm 9 \mathrm{mmHg}$, nitrate supplementation $124 \pm 13 \mathrm{mmHg} ; F_{(2,22)}=0.87, P$ = 0.43), diastolic blood pressure (Baseline, $79 \pm 10 \mathrm{mmHg}$, Placebo $74 \pm 10 \mathrm{mmHg}$, nitrate supplementation $76 \pm 11 \mathrm{mmHg} ;(2,22)=2.81, P=0.08)$ or mean arterial blood pressure (Baseline, $94 \pm 11 \mathrm{mmHg}$, Placebo $90 \pm 9 \mathrm{mmHg}$, nitrate supplementation $92 \pm 11 \mathrm{mmHg}$; $(2,22)=2.29, P=0.13)$ when compared to Placebo and Baseline.

\subsection{Discussion}

This is the first study to examine the effects of nitrate supplementation in the form of concentrated beetroot juice on extremity rewarming following a cold stimulus in individuals with cold sensitivity. Contrary to our hypotheses, acute nitrate supplementation did not alter extremity rewarming, endothelial function, blood pressure, pain or thermal comfort and sensation. This was despite a physiologically meaningful rise in plasma nitrite concentrations in the nitrate supplementation condition (Figure 2).

Plasma nitrate and nitrite increased by $703.6 \mu \mathrm{M}$ and $423.5 \mathrm{nM}$ respectively following ingestion of beetroot juice containing $11.9 \mathrm{mmol}$ of nitrate. This change from baseline in plasma nitrite concentration following nitrate supplementation is similar to that reported in other studies with similar supplementation regimes such as Webb et al. (2008) and Wylie et al. (2013) who report changes of $180 \mathrm{nM}$ and $395 \mathrm{nM}$ respectivley. We would note that due to our protocol design (venous blood samples were taken 1.5 hours post ingestion which is approximately 1 hour prior to peak plasma nitrate and nitrite concentrations (Wylie et al., 2013)) we cannot preclude that nitrate and nitrate values maybe higher than what we have reported. This was done in order to enable the primary outcomes to be measured at the time of peak plasma nitrite concentration.

441 There was no effect of nitrate supplementation on peripheral blood flow and skin temperature following exposure to a cold stimulus when compared to Placebo or Baseline (Figure 3 and Table 1). As a consequence nitrate supplementation did not improve thermal sensation, thermal comfort or reduce the associated pain with the cold stimulus when compared to Placebo or Baseline (Table 2). These findings were in contrast to our previous study which showed that organic nitrate (GTN spray) increased peripheral blood flow and skin temperature in drug naive individuals with cold sensitivity (Hope et al., 2014). The 
disparity between the findings in our two studies is likely due to any combination of the differences between inorganic nitrate and organic nitrates, such as their pharmacokinetics, pharmacodynamics and bio-activation (Janero et al., 2004, Gilchrist et al., 2011, Omar et al., 2012). Elucidating which of these differences were responsible for the lack of effect in peripheral blood flow in the current study requires further investigation. Irrespective of which of these differences are responsible for the lack of effect seen in this trial, it is difficult to compare organic and inorganic nitrates as NO donors. For instance, $80-90 \%$ of GTN is metabolised by liver (Münzel et al., 2005) whereas, the oral microflora within the mouth are an essential component for the processing of inorganic nitrite production and subsequent NO production (Duncan et al., 1995). These differences, among others are reviewed elsewhere by Münzel et al. (2005) and Omar et al. (2012).

Elevations in reactive oxygen species have been shown in rat models of $\mathrm{NFCl}$ (Geng et al., 2015) but have yet to be shown in individuals with cold sensitivity. However, individuals with cold sensitivity have significantly impaired microvasculature (see Figure 1 for comparison to the "normal" response) and therefore redox balance may be altered in favour of a pro-oxidant state (Bertuglia and Giusti, 2003). This would result in a reduced bioavailability of $\mathrm{NO} \bullet$, principally via uncoupling of endothelial nitric oxide synthase and reduction of tetrahydrobiopterin (Landmesser et al., 2003) which leads to an increase of superoxide's and peroxynitrite. Further research is required to determine whether this subclinical population have elevated levels of oxidative stress and whether chronic, rather than acute, beetroot juice supplementation would alter this redox balance thus restoring endothelial function. As individuals with cold sensitivity have cooler extremities they are likely to have diminished eNOS activity reducing NO• production (Kellogg et al., 2008). Longer term nitrate supplementation may alleviate these reductions in the NO pool. Moreover, recent data have shown that nitrate supplementation may reduce sympathetic nervous activity (Notay et al., 2017) which may also be beneficial to individuals with cold sensitivity.

Skin blood flow and temperature were lower in the toes than fingers during the cold sensitivity test (Figure 3; Table 1) and whilst all participants had cold sensitive feet, only one participant had cold sensitive hands. This is despite their self-reported cold exposures to involve the hands and feet to similar degrees. This supports a recent study which reported a 
heterogeneous response of the hands and feet to a cold challenge (Norrbrand et al., 2017) and that the feet appear to be more susceptible to cold injury than the hands (DeGroot et al., 2003, Golden et al., 2013).

There was no effect of nitrate supplementation on the skin blood flow response to transdermal delivery of $\mathrm{ACh}$ in the forearm, finger or foot when compared to Placebo. A previous study in patients with type 2 diabetes also showed no effect of nitrate supplementation on the response to ACh (Gilchrist et al. 2013). Other studies have reported nitrate supplementation resulted in an increase in CVC in the response to local (Keen et al., 2014) and whole body (Levitt et al., 2015) heating in healthy individuals. The increase in CVC in these two studies was a function of a decreased MAP since raw flux data was not altered by nitrate supplementation, as in the current study. Differences in nitrate supplementation regime (a 3 day [ $5 \mathrm{mmol} /$ day] supplementation vs an acute dose 1.5 hours [ 12 mmol] prior to testing) and the lack of a placebo in the other studies could explain the lack of effect of nitrate supplementation on MAP in the current study. It is possible that a longer supplementation period may augment ACh-induced vasodilation in the peripheral microvasculature. This study was designed to have peak plasma nitrite concentrations ( 3 hours post ingestion) during our primary outcome testing (cold sensitivity test) which means that the iontophoresis (endothelial function test) was likely to have been conducted at lower concentrations of plasma nitrite. We therefore, cannot exclude that, if the iontophoresis was conducted at peak plasma nitrite concentrations that nitrate supplementation could have been beneficial.

There was no difference in systolic, diastolic or mean arterial BP following acute nitrate supplementation compared to Baseline or Placebo. Studies investigating short term nitrate supplementation and its effects on blood pressure in clinical populations with endothelial dysfunction have resulted in conflicting reports. For example, reductions in systolic blood pressure have been shown in individuals with chronic obstructive pulmonary disease (COPD) (Berry et al., 2014, Leong et al., 2015, Kerley et al., 2015) and hypertension (Kapil et al., 2015) whilst in contrast, other studies have found no effect in individuals with COPD (Shepherd et al., 2015b, Curtis et al., 2014), type 2 diabetes (Gilchrist et al., 2013, Shepherd et al., 2015a) and heart failure (Zamani et al., 2015). Differences between these studies include, dosing strategies ( $\sim$ vs $\sim 12 \mathrm{mmol}$ ), timing of the supplement (ranging from 1.5 
hours to 4 days which may affect peak plasma nitrite concentrations (Leong et al., 2015)) and importantly, some studies did not include a true placebo (Berry et al., 2014, Kerley et al., 2015). Peak plasma nitrite and corresponding BP reductions typically occur at 2.5 to 4 hours post nitrate ingestion (Wylie et al., 2013). We measured BP indices at 1.5 hours post ingestion for pragmatic reasons, therefore we are likely to have missed the peak in plasma nitrite concentration and cannot exclude that the lack of effect on BP maybe due to timing. Larger, well controlled studies are needed in clinical cohorts to elucidate if any clinically meaningful benefits of short term dietary nitrate supplementation exist as the evidence to date is equivocal.

The main strength to this study is the rigorous experimental design (a double blind, placebo controlled, crossover, randomised control trial). As the current study examined acute supplementation, future research should explore the potential benefits of longer supplementation periods and examine if increasing the bioavailability of nitric oxide could improve endothelial function and microvascular responses to a cold challenge in individuals with impaired peripheral blood flow (e.g. non-freezing cold injury, Raynaud's phenomenon and Scleroderma). A limitation to this study is that we did not measure change in redox balance. Antioxidants and polyphenols in the beetroot juice have the potential to alter NOx bioavailability. Given that the antioxidant and polyphenol content are the same for the nitrate enriched (nitrate supplementation) and depleted (Placebo) beetroot juices (Shepherd et al., 2015a) and that we showed no difference between baseline, placebo or nitrate supplementation conditions for any variable, it is unlikely that the acute consumption of beetroot and associated antioxidant / polyphenol content will have had any effect.

\subsection{Conclusion}

534 This is the first study to examine the effects of inorganic nitrate supplementation in the form of concentrated beetroot juice ingestion on rewarming following a cold stimulus in individuals with cold sensitivity. Despite a physiologically meaningful rise in plasma nitrite concentrations, acute nitrate supplementation did not alter extremity rewarming, endothelial function, blood pressure, pain or thermal comfort and sensation. Although we cannot preclude the possibility that a chronic nitrate supplementation regime could improve extremity rewarming and microvascular function in cold sensitive individuals, acute nitrate 
supplementation does not appear to improve vascular function in this sub-clinical population following acute cold exposure.

\subsection{Acknowledgments:}

544

545

We would like to thank the participants for volunteering for this study, and for assistance from the technicians and Daniel Bailey during data collection. We gratefully acknowledge the funding from the University of Portsmouth.

\subsection{Contribution Statement}

$\mathrm{CE}, \mathrm{JC}, \mathrm{SB}, \mathrm{MG}, \mathrm{HM}$, and $\mathrm{AS}$ were involved in the conception of this work. $\mathrm{CE}, \mathrm{JC}, \mathrm{HM}$, and $\mathrm{AS}$ were involved in the acquisition of data. All authors have been involved in the drafting of this work and revisions for intellectually important content.

\subsection{References}

1. ANDERSON, M., MOORE, T., HOLLIS, S., JAYSON, M., KING, T. \& HERRICK, A. 2002. Digital vascular response to topical glyceryl trinitrate, as measured by laser Doppler imaging, in primary Raynaud's phenomenon and systemic sclerosis. Rheumatology, 41, 324-328.

2. BAHRA, M., KAPIL, V., PEARL, V., GHOSH, S. \& AHLUWALIA, A. 2012. Inorganic nitrate ingestion improves vascular compliance but does not alter flow-mediated dilatation in healthy volunteers. Nitric Oxide, 26, 197-202.

3. BATEMAN, R. M., ELLIS, C. G. \& FREEMAN, D. J. 2002. Optimization of Nitric Oxide Chemiluminescence Operating Conditions for Measurement of Plasma Nitrite and Nitrate. Clinical Chemistry, 48, 570-573.

4. BENJAMIN, N., O'DRISCOLL, F., DOUGALL, H., DUNCAN, C., SMITH, S., GOLDEN, M. \& MCKENZIE, H. 1994. Stomach NO synthesis. Nature, 368, 502.

5. BERRY, M. J., JUSTUS, N. W., HAUSER, J. I., CASE, A. H., HELMS, C. C., BASU, S., ROGERS, Z., LEWIS, M. T. \& MILLER, G. D. 2014. Dietary nitrate supplementation improves exercise performance and decreases blood pressure in COPD patients. Nitric Oxide, 48, 22-30.

6. BERTUGLIA, S. \& GIUSTI, A. 2003. Microvascular oxygenation, oxidative stress, NO suppression and superoxide dismutase during postischemic reperfusion. American Journal of Physiology-Heart and Circulatory Physiology, 285, H1064-H1071.

7. BRYAN, N., S \& HORD, N., G. 2010. Dietary nitrate and nitrites: The physiological context for potential health benefits/ Food, nutrition and the nitric oxide pathway, DEStech Publications.

8. CARLSTRÖM, M., LARSEN, F. J., NYSTRÖM, T., HEZEL, M., BORNIQUEL, S., WEITZBERG, E. \& LUNDBERG, J. O. 2010. Dietary inorganic nitrate reverses features of metabolic syndrome in endothelial nitric oxide synthase-deficient mice. Proceedings of the National Academy of Sciences, 107, 17716-17720.

9. CATTERMOLE, T. J. 1999. The epidemiology of cold injury in Antarctica. Aviation, space, and environmental medicine, 70, 135-140.

10. COSBY, K., PARTOVI, K., CRAWFORD, J., H, PATEL, R., P, REITER, C., D, MARTYR, S., YANG, B., K, WACLAWIW, M., A, ZALOS, G., XU, X., HUANG, K., T, SHIELDS, H., KIM-SHAPIRO, D., B, SCHECHTER, A., N, CANNON III, R., O \& GLADWIN, M., T 2003. Nitrite reduction to nitric 
oxide by deoxyhemoglobin vasodiltaes the human circulation. Nature Medicine. 9, 14981505.

11. CURTIS, K., TANNER, R., O'BRIEN, K., POLKEY, M., EDWARDS, L. \& HOPKINSON, N. 2014. M144 acute dietary nitrate supplementation reduces the oxygen cost of submaximal exercise in COPD. Thorax, 69, A215-A215.

12. DAVEY, M., EGLIN, C., HOUSE, J. \& TIPTON, M. 2013. The contribution of blood flow to the skin temperature responses during a cold sensitivity test. European journal of applied physiology, 113, 2411-2417.

13. DEGROOT, D. W., CASTELLANI, J. W., WILLIAMS, J. O. \& AMOROSO, P. J. 2003. Epidemiology of US Army cold weather injuries, 1980-1999. Aviation, space, and environmental medicine, 74, 564-570.

14. DUNCAN, C., DOUGALL, H., JOHNSTON, P., GREEN, S., BROGAN, R., SMITH, L., GOLDEN, M. \& BENJAMIN, N. 1995. Chemical generation of nitric oxide in the mouth from the entrosalivery circulation of dietary nitrate. Nature Medicine, 1, 546-551.

15. EGLIN, C. Cold sensitivity in windsurfers. International conference on Environmental Ergonomics, 2011 Nafplio, Greece. 389.

16. EGLIN, C. M., GOLDEN, F. S. \& TIPTON, M. J. 2013. Cold sensitivity test for individuals with non-freezing cold injury: the effect of prior exercise. Extreme Physiology \& Medicine, 2, 1.

17. FERGUSON, S. K., GLEAN, A. A., HOLDSWORTH, C. T., WRIGHT, J. L., FEES, A. J., COLBURN, T. D., STABLER, T., ALLEN, J. D., JONES, A. M., MUSCH, T. I. \& POOLE, D. C. 2016. Skeletal Muscle Vascular Control During Exercise: Impact of Nitrite Infusion During Nitric Oxide Synthase Inhibition in Healthy Rats. J Cardiovasc Pharmacol Ther, 21, 201-8.

18. FERREIRA-VALENTE, M. A., PAIS-RIBEIRO, J. L. \& JENSEN, M. P. 2011. Validity of four pain intensity rating scales. $P A I N^{\circledR}, 152,2399-2404$.

19. FRASER, I. \& LOFTUS, J. A. 1979. " Trench foot" caused by the cold. British medical journal, 1, 414.

20. GARDNER-MEDWIN, J., MACDONALD, I., TAYLOR, J., RILEY, P. \& POWELL, R. 2001. Seasonal differences in finger skin temperature and microvascular blood flow in healthy men and women are exaggerated in women with primary Raynaud's phenomenon. British journal of clinical pharmacology, 52, 17-23.

21. GENG, Z., TONG, X. \& JIA, H. 2015. Reactive oxygen species (ROS) mediates non-freezing cold injury of rat sciatic nerve. International Journal of Clinical and Experimental Medicine, 8, 15700-15707.

22. GILCHRIST, M., SHORE, A. C. \& BENJAMIN, N. 2011. Inorganic nitrate and nitrite and control of blood pressure. Cardiovascular Research, 89, 492-498.

23. GILCHRIST, M., WINYARD, P. \& BENJAMIN, N. 2010. Dietary Nitrate - Good or bad? Nitric Oxide, 22, 104-109.

24. GILCHRIST, M., WINYARD, P. G., AIZAWA, K., ANNING, C., SHORE, A. \& BENJAMIN, N. 2013. Effect of dietary nitrate on blood pressure, endothelial function, and insulin sensitivity in type 2 diabetes. Free Radical Biology and Medicine, 60, 89-97.

25. GILCHRIST, M., WINYARD, P. G., FULFORD, J., ANNING, C., SHORE, A. \& BENJAMIN, N. 2014. Dietary nitrate supplementation improves reaction time in type 2 diabetes: Development and application of a novel nitrate-depleted beetroot juice placebo. Nitric Oxide.

26. GOLDEN, F. S. C., FRANCIS, T. J. R., GALLIMORE, D. \& PETHYBRIDGE, R. 2013. Lessons from history: morbidity of cold injury in the Royal Marines during the Falklands Conflict of 1982. Extreme physiology \& medicine, 2, 23.

27. GOVONI, M., JANSSON, E. Å., WEITZBERG, E. \& LUNDBERG, J. O. 2008. The increase in plasma nitrite after a dietary nitrate load is markedly attenuated by an antibacterial mouthwash. Nitric Oxide, 19, 333-337. 
28. HODGES, G. J., ZHAO, K., KOSIBA, W. A. \& JOHNSON, J. M. 2006. The involvement of nitric oxide in the cutaneous vasoconstrictor response to local cooling in humans. The Journal of physiology, 574, 849-857.

29. HOPE, K., EGLIN, C., GOLDEN, F. \& TIPTON, M. 2014. Sublingual glyceryl trinitrate and the peripheral thermal responses in normal and cold-sensitive individuals. Microvasc Res, 91, 849.

30. HOUSE, C., TAYLOR, R. \& OAKLEY, E. 2015. Repeatability of a cold stress test to assess cold sensitization. Occupational Medicine, 65, 578-584.

31. HSI, D. H., ROSHANDEL, A., SINGH, N., SZOMBATHY, T. \& MESZAROS, Z. S. 2005. Headache response to glyceryl trinitrate in patients with and without obstructive coronary artery disease. Heart, 91, 1164-1166.

32. IMRAY, C., GRIEVE, A., DHILLON, S. \& GROUP, C. X. E. R. 2009. Cold damage to the extremities: frostbite and non-freezing cold injuries. Postgraduate medical journal, 85, 481488.

33. JANERO, D. R., BRYAN, N. S., SAIJO, F., DHAWAN, V., SCHWALB, D. J., WARREN, M. C. \& FEELISCH, M. 2004. Differential nitros (yl) ation of blood and tissue constituents during glyceryl trinitrate biotransformation in vivo. Proceedings of the National Academy of Sciences of the United States of America, 101, 16958-16963.

34. KAPIL, V., KHAMBATA, R. S., ROBERTSON, A., CAULFIELD, M. J. \& AHLUWALIA, A. 2015. Dietary Nitrate Provides Sustained Blood Pressure Lowering in Hypertensive Patients: A Randomized, Phase 2, Double-Blind, Placebo-Controlled Study. Hypertension, 65, 320-327.

35. KEEN, J. T., LEVITT, E. L., HODGES, G. J. \& WONG, B. J. 2014. Short-term dietary nitrate supplementation augments cutaneous vasodilatation and reduces mean arterial pressure in healthy humans. Microvascular research.

36. KELLOGG, D. L., ZHAO, J. L. \& WU, Y. 2008. Endothelial nitric oxide synthase control mechanisms in the cutaneous vasculature of humans in vivo. American Journal of Physiology. Heart and Circulatory Physiology, 295, H123-H129.

37. KENJALE, A. A., HAM, K. L., STABLER, T., ROBBINS, J. L., JOHNSON, J. L., VANBRUGGEN, M., PRIVETTE, G., YIM, E., KRAUS, W. E. \& ALLEN, J. D. 2011. Dietary nitrate supplementation enhances exercise performance in peripheral arterial disease. Journal of Applied Physiology, $110,1582-1591$.

38. KERLEY, C. P., CAHILL, K., BOLGER, K., MCGOWAN, A., BURKE, C., FAUL, J. \& CORMICAN, L. 2015. Dietary nitrate supplementation in COPD: An acute, double-blind, randomized, placebo-controlled, crossover trialis. Nitric Oxide, 44, 105-111.

39. KETEL, I. J., STEHOUWER, C. D., SERNÉ, E. H., POEL, D. M., GROOT, L., KAGER, C., HOMPES, P. G., HOMBURG, R., TWISK, J. W. \& SMULDERS, Y. M. 2009. Microvascular function has no menstrual-cycle-dependent variation in healthy ovulatory women. Microcirculation, 16, 714724.

40. LADEN, G. D., PURDY, G. \& O'RIELLY, G. 2007. Cold Injury to a Diver's Hand After a 90-min Dive in $6^{\circ} \mathrm{C}$ Water. Aviation, space, and environmental medicine, 78, 523-525.

41. LANDMESSER, U., DIKALOV, S., PRICE, S. R., MCCANN, L., FUKAI, T., HOLLAND, S. M., MITCH, W. E. \& HARRISON, D. G. 2003. Oxidation of tetrahydrobiopterin leads to uncoupling of endothelial cell nitric oxide synthase in hypertension. J Clin Invest, 111, 1201-9.

42. LEONG, P., BASHAM, J. E., YONG, T., CHAZAN, A., FINLAY, P., BARNES, S., BARDIN, P. G. \& CAMPBELL, D. 2015. A double blind randomized placebo control crossover trial on the effect of dietary nitrate supplementation on exercise tolerance in stable moderate chronic obstructive pulmonary disease. BMC Pulm Med, 15, 52 ..

43. LEVITT, E. L., KEEN, J. T. \& WONG, B. J. 2015. Augmented reflex cutaneous vasodilatation following short-term dietary nitrate supplementation in humans. Experimental physiology, 6, 708-718. 
44. LUNDBERG, J. O. \& GOVONI, M. 2004. Inorganic nitrate is a possible source for systemic generation of nitric oxide. Free Radical Biology and Medicine, 37, 395-400.

45. LUNDBERG, J. O. \& WEITZBERG, E. 2005. NO generation from nitrite and its role in vascular control. Arteriosclerosis, Thrombosis, and Vascular Biology, 25, 915-922.

46. LUNDBERG, J. O., WEITZBERG, E. \& GLADWIN, M. T. 2008. The nitrate-nitrite-nitric oxide pathway in physiology and therapeutics. Nature Reviews Drug Discovery, 7, 156-167.

47. LUNT, H. \& TIPTON, M. 2014. Differences in conductive foot cooling: a comparison between males and females. European journal of applied physiology, 114, 2635-2644.

48. MALEY, M. J., HOUSE, J. R., TIPTON, M. J. \& EGLIN, C. M. 2017. Role of cyclooxygenase in the vascular response to locally delivered acetylcholine in Caucasian and African descent individuals. Microvascular research, 111, 80-87.

49. MILLS, W. \& MILLS, W. 1993. Peripheral non-freezing cold injury: immersion injury. Alaska medicine, 35, 117-128.

50. MINSON, C. T., BERRY, L. T. \& JOYNER, M. J. 2001. Nitric oxide and neurally mediated regulation of skin blood flow during local heating. Journal of Applied Physiology, 91, 16191626.

51. MONTGOMERY, H. \& HORWITZ, O. 1950. OXYGEN TENSION OF TISSUES BY THE POLAROGRAPHIC METHOD. I. INTRODUCTION: OXYGEN TENSION AND BLOOD FLOW OF THE SKIN OF HUMAN EXTREMITIES. Journal of Clinical Investigation, 29, 1120-1130.

52. MONTGOMERY, H., HORWITZ, O., PEIRCE, G. \& SAYEN, A. 1954. Experimental Immersion Foot. I. The Effects of Prolonged Exposure to Water at $3^{\circ} \mathrm{C}$. on the Oxygen Tension AND Temperature of the Rabbit Leg. The Journal of Clinical Investigation, 33, 361-369.

53. MOREIRA, D. G., COSTELLO, J. T., BRITO, C. J., ADAMCZYK, J. G., AMMER, K., BACH, A. J., COSTA, C. M., EGLIN, C., FERNANDES, A. A. \& FERNÁNDEZ-CUEVAS, I. 2017. Thermographic imaging in sports and exercise medicine: a Delphi study and consensus statement on the measurement of human skin temperature. Journal of Thermal Biology.

54. MÜNZEL, T., DAIBER, A. \& MÜLSCH, A. 2005. Explaining the phenomenon of nitrate tolerance.

Circulation research, 97, 618-628.

55. NEEDLEMAN, P. \& JOHNSON, E. M. 1973. Mechanism of tolerance development to organic nitrates. Journal of Pharmacology and Experimental Therapeutics, 184, 709.

56. NORRBRAND, L., KÖLEGÅRD, R., KERAMIDAS, M. E., MEKJAVIC, I. B. \& EIKEN, O. 2017. No association between hand and foot temperature responses during local cold stress and rewarming. European Journal of Applied Physiology, 1-13.

57. NOTAY, K., INCOGNITO, A. V. \& MILLAR, P. J. 2017. Acute beetroot juice supplementation on sympathetic nerve activity: A randomized, double-blind, placebo-controlled proof-ofconcept study. American Journal of Physiology-Heart and Circulatory Physiology, ajpheart. 00163.2017.

58. OMAR, S. A., ARTIME, E. \& WEBB, A. J. 2012. A comparison of organic and inorganic nitrates/nitrites. Nitric Oxide, 26, 229-240.

59. O'REILLY, D., TAYLOR, L., EL-HADIDY, K. \& JAYSON, M. 1992. Measurement of cold challenge responses in primary Raynaud9s phenomenon and Raynaud9s phenomenon associated with systemic sclerosis. Annals of the rheumatic diseases, 51, 1193-1196.

60. SHEFFIELD, C. W., SESSLER, D. I., HOPF, H. W., SCHROEDER, M., MOAYERI, A., HUNT, T. K. \& WEST, J. M. 1996. Centrally and locally mediated thermoregulatory responses alter subcutaneous oxygen tension. Wound Repair and Regeneration, 4, 339-345.

61. SHEPHERD, A. I., GILCHRIST, M., WINYARD, P. G., JONES, A. M., HALLMANN, E., KAZIMIERCZAK, R., REMBIALKOWSKA, E., BENJAMIN, N., SHORE, A. C. \& WILKERSON, D. P. 2015a. Effects of dietary nitrate supplementation on the oxygen cost of exercise and walking performance in individuals with type 2 diabetes: a randomized, double-blind, placebocontrolled crossover trial. Free Radical Biology and Medicine, 86, 200-208. 
62. SHEPHERD, A. I., WILKERSON, D. P., DOBSON, L., KELLY, J., WINYARD, P. G., JONES, A. M., BENJAMIN, N., SHORE, A. C. \& GILCHRIST, M. 2015b. The effect of dietary nitrate supplementation on the oxygen cost of cycling, walking performance and resting blood pressure in individuals with chronic obstructive pulmonary disease: A double blind placebo controlled, randomised control trial. Nitric Oxide, 48, 31-37.

63. SHEPHERD, A. I., WILKERSON, D. P., FULFORD, J., WINYARD, P. G., BENJAMIN, N., SHORE, A. C. \& GILCHRIST, M. 2016. Effect of nitrate supplementation on hepatic blood flow and glucose homeostasis: A double-blind, placebo controlled, randomised control trial. American Journal of Physiology-Gastrointestinal and Liver Physiology, ajpgi. 00203.2016.

64. STAMLER, J. S., JIA, L., EU, J. P., MCMAHON, T. J., DEMCHENKO, I. T., BONAVENTURA, J., GERNERT, K. \& PIANTADOSI, C. A. 1997. Blood flow regulation by S-nitrosohemoglobin in the physiological oxygen gradient. Science, 276, 2034-7.

65. THOMPSON, C., WYLIE, L. J., BLACKWELL, J. R., FULFORD, J., BLACK, M. I., KELLY, J., MCDONAGH, S. T., CARTER, J., BAILEY, S. J. \& VANHATALO, A. 2017. Influence of dietary nitrate supplementation on physiological and muscle metabolic adaptations to sprint interval training. Journal of Applied Physiology, 122, 642-652.

66. WEBB, A., J, PATEL, N., LOUKOGEORGAKIS, S., OKORIE, M., ABOUD, Z., MISRA, S., RASHID, R., MIALL, P., DEANFIELD, J., BENJAMIN, N., MACALLISTER, R., HOBBS, A., J \& AHLUWALIA, A. 2008. Acute Blood Pressure Lowering, Vasoprotective, and Antiplatelet Properties of Dietary Nitrate via Bioconversion to Nitrite. Hypertension, 51, 784-790.

67. WILLIAMS, G. L., MORGAN, A. E. \& HARVEY, J. S. 2005. Trench foot following a collapse: assessment of the feet is essential in the elderly. Age and ageing, 34, 651-652.

68. WRENN, K. 1991. Immersion foot: A problem of the homeless in the 1990s. Archives of internal medicine, 151, 785-788.

69. WYLIE, L. J., KELLY, J., BAILEY, S. J., BLACKWELL, J. R., SKIBA, P. F., WINYARD, P. G., JEUKENDRUP, A. E., VANHATALO, A. \& JONES, A. M. 2013. Beetroot juice and exercise: pharmacodynamic and dose-response relationships. J Appl Physiol, 115, 325-36.

70. ZAMANI, P., RAWAT, D., SHIVA-KUMAR, P., GERACI, S., BHUVA, R., KONDA, P., DOULIAS, P. T., ISCHIROPOULOS, H., TOWNSEND, R. R., MARGULIES, K. B., CAPPOLA, T. P., POOLE, D. C. \& CHIRINOS, J. A. 2015. Effect of inorganic nitrate on exercise capacity in heart failure with preserved ejection fraction. Circulation, 131, 371-80.

71. ZHANG, H., HUIZENGA, C., ARENS, E. \& WANG, D. 2004. Thermal sensation and comfort in transient non-uniform thermal environments. European journal of applied physiology, 92, 728-733. 